\title{
Culture of freshwater zooplankton Daphnia magna fed with different feed combination
}

\author{
MONOWAR ASIF KHAN, MD. MOHIBUL HASAN, KIZAR AHMED SUMON \\ AND HARUNUR RASHID* \\ Department of Fisheries Management \\ Bangladesh Agricultural University, Mymensingh 2202, Bangladesh \\ *Email: rashid@bau.edu.bd
}

\begin{abstract}
The study was focused on the culture of freshwater zooplankton Daphnia magna under different feed trials. D. magna was collected from a pond and isolated based on its distinct morphological characteristics. They were cultured in 12 glass jars containing $700 \mathrm{~mL}$ of tap water with different feeding regimes: control (tap water only), green water $(25 \mathrm{ml} / \mathrm{L})(\mathrm{Tg})$, yeast $(50 \mathrm{~g} / \mathrm{L})+$ green water $(25 \mathrm{ml} / \mathrm{L})(\mathrm{Tyg})$ and yeast $(16.6 \mathrm{~g} / \mathrm{L})+$ powdered green pea $(16.6 \mathrm{~g} / \mathrm{L})+$ brown flour $(16.6 \mathrm{~g} / \mathrm{L})(\mathrm{Tygb})$. Each of the control and feed trials was set up in three replicates. Feeding and population count took place every third day over an experimental duration of 21 days. The highest population density of $D$. magna was found in Tyg on day 15 , which was 207.1 individuals/L and the lowest was found in control, which was 23.80 individuals/L. Results showed relatively better growth performance of $D$. magna in mixed feed trials compared to single or 'no feed' trial. Among three feed trials, Tyg incurred the lowest cost compared to others and the cost to production ratio was 7.8 . The culture technique that have been standardized in the present study could be applied to fish hatcheries and nurseries in Bangladesh.
\end{abstract}

Keywords: Zooplankton, Daphnia magna, Live food

\section{Introduction}

Live foods are natural sources of proteins, lipids, carbohydrates, minerals and vitamins (Jorge et al. 2016). Daphnia magna is highly nutritious live food containing $45-70 \%$ of protein and 11$27 \%$ of lipid (Macedo and Pinto-Coelho 2001). They are small planktonic cladocerans (adult length $1.5-5.0 \mathrm{~mm}$ ) or typical water flea that belong to the family Daphniidae. Live foods are able to swim in water column and are constantly available to fish and shellfish larvae (David 2003). D. magna can reproduce both asexually and sexually having a parthenogenetic life cycle, exhibiting heterogenic reproduction (Alekseev and Lampert 2001).

Larval rearing is one of the riskiest phases of aquaculture especially in hatchery condition, but it could be one of the most profitable venture. Considering the growing need for live food by fish hatcheries and nurseries, it is essential to develop a culture technique of freshwater zooplankton and popular live food for fish larvae. Therefore, special planning and strategy in developing a culture technique of D. magna is required to overcome the risk of high mortality during this phase of culture. Copepods and cladocerans both can meet the nutritional requirements of fish larvae (Evjemo et al. 2003, Sumon 2018). Due to high cost of Artemia cysts and lack of their availability, cheaper alternative diets with similar nutritional quality is needed to maintain the cost competitiveness of the fish in the global market. Fish require protein rich live food for their better growth, efficient breeding and survival (Mandal et al. 2009). The success in the hatchery production of fish fingerlings for stocking in the grow-out production system is largely dependent on the availability of suitable live food for feeding fish larvae, fry and fingerlings (Lim et al. 2003). 
Live food can be purchased from the market, which is often costly. But these live foods can be cultured easily at low-cost. Before culture, isolation of D. magna from other planktons is mandatory. Cladocerans have the advantage of high reproduction rates, wide temperature tolerance and the ability to thrive on phytoplankton and organic wastes (Bogut et al. 2000). Both quality and amount of available food affect different aspects of Daphnia biology, such as feeding rate (Lampert and Brendelberger 1996, Kilham et al. 1997, Lari et al. 2017), growth (Elser et al. 2001, Acharya et al. 2004), survival (Sundbom and Vrede 1997) and reproduction (Sundbom and Vrede 1997, Schulz and Sterner 2000). Therefore, the degree of success in finding highquality food influences Daphnia population dynamics (Lari et al. 2018). Development of a culture technique would assist to establish an ideal food for $D$. magna. The culture technique of D. magna would also assist the hatchery owners including fish farmers due to its' low cost, easy availability and simple culture technique. Hence, the objectives of the study were to develop the culture technique and to evaluate the growth performance of $D$. magna under different feed trials.

\section{Materials and Methods}

Collection and isolation of zooplankton: Zooplankton were collected from Sharnalata Agro Fisheries Ltd., Fulbaria upazila, Mymensingh District, Bangladesh in January 2019. Mixed population of zooplankton e.g. rotifers, copepods and cladocerans were obtained from ponds through zooplankton net (mesh size: $0.04 \mathrm{~mm}$ ) with the help of local fishermen. Zooplankton were collected in ten plastic bottles $(5 \mathrm{~L})$. The plastic bottles were brought back to the Aquatic Conservation Laboratory, Faculty of Fisheries, Bangladesh Agricultural University. About 100 $\mathrm{mL}$ water was taken in a glass vial from each of the ten plastic bottles. Then single zooplankton was taken into a Petri dish with the help of a fine dropper $(5 \mathrm{~mL})$ and carefully placed under light microscope (Classic LED, Humascope) to identify the D. magna with the help of distinct morphological characteristics.

Experimental design: For the present study, each of the 28 individuals of $D$. magna was transferred into each of the twelve 1-L glass jars containing $700 \mathrm{~mL}$ of tap water. Glass jars were covered with Marcin cloth to protect D. magna from insect. The experimental design was consisted of three different feed trials: control (tap water only), green water $(25 \mathrm{ml} / \mathrm{L})(\mathrm{Tg})$, yeast $(50 \mathrm{~g} / \mathrm{L})$ plus green water $(25 \mathrm{ml} / \mathrm{L})(\mathrm{Tyg})$ and yeast $(16.6 \mathrm{~g} / \mathrm{L})$ plus powdered green pea $(16.6 \mathrm{~g} / \mathrm{L})$ plus brown flour $(16.6 \mathrm{~g} / \mathrm{L})$ (Tygb). Each of the control and treatments was maintained in three replicates over a period of 21 days. Feed was applied in the glass jars every three days. The counting of $D$. magna took place every three days just before the feed was supplied. Water quality parameters (i.e. temperature, DO, $\mathrm{pH}$ and total alkalinity) were monitored every third day. Temperature was measured using a mercury thermometer. $\mathrm{pH}$ and DO of water samples were determined with a digital $\mathrm{pH}$ meter (HI-8424) and a DO meter (Lutron DO-5509), respectively. Total alkalinity of water was estimated using titration method described in American Public Health Association (APHA 2005). The values of water quality parameters in the experimental units were as follows: temperature $\left(17.9-25.6{ }^{\circ} \mathrm{C}\right)$, DO $(5.0-6.3$ $\mathrm{mg} / \mathrm{L}), \mathrm{pH}(6.8-8.4)$, and total alkalinity $(128-170 \mathrm{mg} / \mathrm{L})$. The culture of $D$. magna was conducted at the Wet Laboratory of the Faculty of Fisheries, Bangladesh Agricultural University, Bangladesh. 
Data analysis: Data were presented as mean \pm SD. In order to assess the differences of the density of $D$. magna among the treatments, we used one-way analysis of variance (One-way ANOVA) followed by Tukey's post hoc test. Statistical significance was set at $p<0.05$. Data were analyzed using SPSS (version 14.0).

\section{Results}

Density of D. magna over culture period: In the present study, the density of D. magna was significantly higher $(p<0.05)$ in different feed trials than that of control on day 6 to onwards. The highest density was observed in Tyg as compared to other treatments for almost all sampling days. After 15 days of the start of the feeding trial, the density was 207.2 individuals/L and after that the density was decreased. The lowest density was 36.7 individuals/L after 21 days. After 15 days, the density in Tg was 124.8 individuals/L. After that, the population density was gradually decreased. The lowest population density was 63.3 individuals/L after 21 days of the start of the experiment. In Tygb, the density of D. magna reached its peak (110.5 individuals/L) after 12 days of culture. After that, the density was gradually decreased. The ultimate density was 64.3 individuals/L after 21 days of the start of the feeding trials. In control, density gradually decreased throughout the culture period. After 3 days of the start of the feeding trial, the population density of D. magna was 23.8 individuals/L. After that, the population density was again decreased in amount from 3 days onwards. The lowest population density in control was 9.9 individuals/L after 21 days of the start of the feeding trials (Fig. 1).

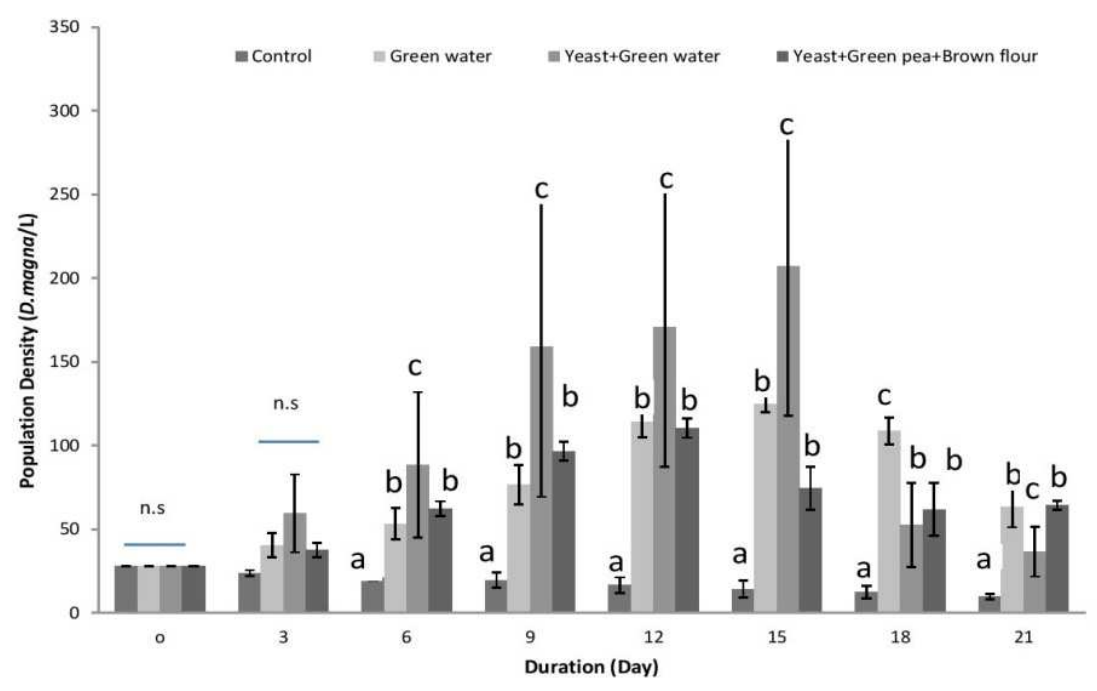

Fig. 1. Mean variation $(\mathrm{N}=3)$ of population density of $D$. manga in different feed trials over the experimental period of 21 days. Different letters indicate a significant difference $(p<0.05)$. 


\section{Discussion}

In the present study, the density of Daphnia magna was observed using different feed trials. It was found that combined diet of yeast plus green water showed (Tyg) the highest population density (207.1 individuals /L) on day 15 of the culture and single diet green water $(\mathrm{Tg})$ (combination of microalgae at a concentration $37.45 \times 10^{4}$ cells) showed comparatively lower production (124.47 individuals/L). This result proved that $D$. magna prefer mixed diet than single diet. Similarly, Jorge et al. (2016) studied the production of D. magna in laboratory condition and reported that $D$. magna preferred combined diet than single diet. In present study, combined diet Tyg showed the highest population density where control treatment showed the lowest population density. No increased population density was found in control which indicated that without any supplemental diet D. magna shows poor growth and reproduction. Almost similar result was also observed for D. pulex by Kumar (2007), where maximum density was observed using Chicken dropping and the minimum density was observed in control (without feed supplement). In the present study, highest population density (207.1 individuals/L) was obtained using instant dry yeast $(50 \mathrm{~g} / \mathrm{L})$ in combination with green water $(25 \mathrm{ml} / \mathrm{L})$. Almost similar results were found in several previous studies in the sense that they also found higher population density of different zooplankton when they were fed with mixed diet than single diet or without feed treatment (Rottman et al. 2002, Farhadian et al. 2012).

In conclusion, the result revealed that Tyg showed the maximum population density of $D$. magna, which was 207.1 individual/L. Furthermore, result also indicated that Tyg showed the lowest cost as compared to other feed trials. Hence, the results of this study suggest that the hatchery owners could use mixed diet (yeast plus green water) for the mass production of $D$. magna.

Acknowledgement: The authors would like to acknowledge the Sharnalata Agro Fisheries Ltd. for the help with the collection of zooplankton.

\section{Literature Cited}

Acharya, K., M. Kyle and J.J. Elser, 2004. Biological stoichiometry of Daphnia growth, an ecophysiological test of the growth rate hypothesis. Limnol. Oceanogr., 49: 656-665.

Alekseev, V. and W. Lampert, 2001. Maternal control of resting-egg production in Daphnia, National Library of Medicine National Institutes of Health, United States. Nature, 404: 899-901.

American Public Health Association (APHA), 2005. Standard Methods for the Examination of Water and Waste Water, twenty-first ed. American Water Works Association and Federal Water Pollution Control Administration, Washington DC, USA. 1193 p.

Bogut, I., I. Adámková, D. Novoselic, Z. Bukvic, Z. Milakovi and D. Kralik, 2000. Influence of lisine on weight gain of carp fry (Cyprinus carpio) in cage and fishpond farming. Czech. J. Anim. Sci., 45: 179-184.

David, A.B., 2003. Status of marine aqua culture in relation to live prey: past, present and future. In: Josianne, G. S and Lesley, A. M. (eds.), Live Feeds in Marine Aquaculture. Blackwell publishing, United Kingdom. 1-16.

Elser, J.J., J. Hayakawa and J. Urabe, 2001, Nutrient limitation reduces food quality for zooplankton: Daphnia response to seston phosphorus enrichment. Ecology, 92: 898-903.

Evjemo, J.O., K.I. Reitanand and Y. Olsen, 2003. Copepods as live food organisms in the larval rearing of halibut larvae (Hippoglossus hippoglossus) with special emphasis on the nutritional value. Aquaculture, 227: 191-210. 
Farhadian, O., M.H. Khanjani, Y. Keivany and E.E. Dorcheh, 2012. Culture experiments with a freshwater Cladoceran (Ceriodaphnia quadrangular) as suitable live food for Mayan cichlid (Cichlasoma urophthalmus) larvae. Brazilian J. Aquat. Sci.Tech., 16: 79-89.

Jorge C.M., O.C.J. Antonio, C.M. German, C.C. Irina, M.D. Carmen and B.C. Daniel, 2016. Laboratory production of Daphnia magna (Straus 1820) fed with microalgae and active dry yeast. $J$. Entomol. Zool. Stud., 4: 548-553.

Kilham, S.S., D.A. Kreeger, C.E. Goulden and S.G. Lynn, 1997. Effects of algal food quality on fecundity and population growth rates of Daphnia. Freshw. Biol., 38: 639-647.

Kumar, D.D., 2007. Development of an indigenous method to culture Daphnia in order to supplement planktonic biomass to young ones of Indian major carp. MS Thesis. Department of Fisheries, College of Agriculture, Indira Gandhi Krishi Vishwavidyalaya Raipur, India.

Lampert, W. and H. Brendelberger, 1996. Strategies of phenotypic low food adaptation in Daphnia: filter screens mesh sizes, and appendage beat rates. Limnol. Oceanogr., 41: 216-223.

Lari, E., D. Steinkey and G.G. Pyle, 2017. A novel apparatus for evaluating contaminant effects on feeding activity and heart rate in Daphnia spp. Ecotoxicol. Environ. Safe., 135: 381-386.

Lari, E., D. Steinkey, R.J. Steinkey and G.G. Pyle, 2018. Daphnia magna increase feeding activity in the presence of four amino acids. J. Plankton Res., 40: 537-543.

Lim, L.C., P. Dhert and P. Sorgeloos, 2003. Recent developments in the application of live feeds in the freshwater ornamental fish culture. Aquaculture, 227: 319-331.

Macedo, C.F. and R.M. Pinto-Coelho, 2001. Nutritional Status Response of Daphnia laevis and Moinamicrurafrom a tropical reservoir to different algal diets: Scenedesmus quadricauda and Ankistrodesmus gracilis. Brazilian J. Biol., 61: 555-562.

Mandal, S.C., P. Das, S.K. Singh and S.K. Bhagabati, 2009. Feeding of aquarium fishes with natural and artificial foods: available options and future needs. Aquac. Int., 3: 20-23.

Rottman, R.W., J.S. Graves, C. Watson and R.P.E. Yanong, 2002. Culture techniques of Moina: the ideal Daphnia for feeding freshwater fish fry. Circular 1054. Institute of Food and Agricultural Sciences. University of Florida. 1-6.

Schulz, K. L. and R.W. Sterner, 2000. Zooplankton food quality in large lakes-growth of Daphnia on high P content seston from Lake Superior. Verh. Internat.Vereinig. Limnol., 27: 1855- 1860.

Sumon, K.A., 2018. Effects of insecticides on aquatic ecosystems in Bangladesh. PhD Thesis. Department of Aquatic Ecology and Water Quality Management, Wageningen University, The Netherlands. https://library.wur.nl/WebQuery/wurpubs/fulltext/455257.

Sundbom, M. and T. Vrede, 1997. Effects of fatty acid and phosphorus content of food on the growth, survival and reproduction of Daphnia. Freshw. Biol., 38: 665-674. 